\title{
SOBRE ELEIÇÕES, FESTIVAIS E RESOLUÇÃO DE PROBLEMAS: FUTEBOL DE VÁRZEA E REDES POLÍTICAS LOCAIS EM BELO HORIZONTE (1962-1965)
}

About elections, festivals and resolution of problems: futebol de várzea and local political networks in Belo Horizonte (1962-1965)

Sobre elecciones, festivales y resolución de problemas: futebol de várzea y redes políticas locales en Belo Horizonte (1962-1965)

\section{RAPHAEL RAJÃO RIBEIRO ${ }^{*}$}

\footnotetext{
' Escola de Clências Sociais da Fundação Getulio Vargas (CPDOC/FGV), Rio de Janeiro - RJ, Brasil.

* Doutorando em História, Política e Bens Culturais (CPDOC/FGV) e técnico nível superior - patrimônio cultural na Fundação Municipal de Cultura de Belo Horizonte. (raprajao@gmail.com). ORCID iD http://orcid.org/0000-0001-7057-8367

Artigo recebido em 29 de junho de 2019 e aprovado para a publicação em 8 de outubro de 2019.
} 


\title{
RESUMO
}

0 presente artigo investiga os vínculos estabelecidos entre clubes de futebol de várzea e líderes políticos de Belo Horizonte no momento final do intervalo democrático. Ao mobilizar fontes impressas e a memória social sobre a prática, busca-se compreender de que maneira essas interações possibilitaram a manutenção de uma modalidade esportiva cada vez mais ameaçada pelas pressões decorrentes da transformação urbana. 0 exame dessas relações permite perceber uma rede de reciprocidade ampla, que se estende para muito além dos períodos eleitorais e da simples troca de favores por votos.

PALAVRAS-CHAVE: Futebol amador; Belo Horizonte; Clientelismo; Reciprocidade.

\begin{abstract}
The present article aims to investigate the connections between futebol de várzea clubs and local political leaders from Belo Horizonte in the final moment of the Brazilian democratic interval in the middle 1960's. Mobilizing press records and the social memory about this practice, aim to understand how these interactions enable the maintenance of this sport increasingly threatened by the pressures of the urban transformation. The examination of these relations allowed realize a large reciprocity network, which extend apart from the elections and the simple act of exchanging favor for votes.
\end{abstract}

KeYwORDs: Amateur football; Belo Horizonte; Clientelism; Reciprocity.

\section{RESUMEN}

El presente artículo investiga los vínculos establecidos entre clubs de futebol de várzea y líderes políticos de Belo Horizonte en el momento final del intervalo democrático brasileño, en medios de los años 1960. Movilizando fuentes impresas y la memoria social acerca de la práctica, se intenta comprender de qué manera esas interacciones posibilitaran la manutención de una modalidad deportiva cada vez más amenazada por las presiones decurrentes de la transformación urbana. El examen de esas relaciones permite percibir una red que se extiende mucho más allá de las elecciones y del simple cambio de favores por votos.

PALABRAS CLAVE: Fútbol amador; Belo Horizonte; Clientelismo; Reciprocidad. 
E m 1962, completavam-se quinze anos desde que o primeiro prefeito eleito de Belo Horizonte assumira o cargo. Foi apenas com o fim do Estado Novo e a consolidação da autonomia da capital - a qual, até então, passara décadas sob a tutela do governo estadual - que coube à população da cidade indicar seu mandatário. Foi justamente nessa primeira administração escolhida pelo sufrágio, de Otacílio Negrão de Lima, que se criou um órgão municipal dedicado ao esporte. Com atuação voltada principalmente para o apoio ao futebol amador, o Conselho Municipal de Esportes (CME) cuidava do fornecimento de materiais e da disponibilização de recursos para a implantação de melhorias nos campos de jogo.

Naquele ano, a capital mineira vivenciava as expectativas do que seria sua quinta eleição municipal. Nylton Velloso, da União Democrática Nacional (UDN), surgia como o principal candidato a prefeito. Com amplo destaque à frente da Federação do Comércio do Estado de Minas Gerais (Fecomércio MG), despontava como favorito na disputa. ${ }^{1}$ Ao seu lado, concorria Jorge Carone Filho, deputado estadual pelo Partido Republicano (PR), que fora prefeito de Visconde de Rio Branco, sua cidade natal. Ele iniciara a campanha havia meses, percorrendo vários bairros da cidade. Carone chamava a atenção por sua altura — havia sido desportista no passado, quando atuou como goleiro do Botafogo do Rio de Janeiro e como halterofilista, sendo campeão nacional da modalidade. ${ }^{2}$

Com menos chances, concorriam outros postulantes, como José Maria Rabelo, do Partido Socialista Brasileiro (PSB) e proprietário do Binômio, reconhecido jornal local articulado aos movimentos sociais. 0 jornalista mobilizava o slogan de campanha janista e se dizia o representante do povo na luta do tostão contra o milhão. ${ }^{3}$

Em meio à disputa eleitoral, diversos grupos sociais se engajavam para que suas pautas e os candidatos que as representavam saíssem vitoriosos. Por vezes, o futebol amador podia ser percebido. Envolvidos nas campanhas, os varzeanos garantiam a relevância do tema como parte da plataforma dos postulantes à prefeitura ou a uma vaga nos poderes legislativos.

Durante os meses de agosto e setembro, Belo Horizonte se agitava com a campanha para as eleições que escolheriam prefeito, vice-prefeito e vereadores da capital mineira, além de selecionarem deputados federais e estaduais. Cada candidato procurava se associar a uma ou mais pautas que fossem capazes de mobilizar a população local e alavancar suas votações. Para tanto, utilizavam estratégias variadas, apostando, em sua maioria, num fator que já se mostrara decisivo nos pleitos anteriores: os setores populares urbanos.

0 deputado estadual Jorge Carone Filho, que intentava nova condução à Assembleia Legislativa, ao mesmo tempo que se lançava como concorrente à prefeitura - o que era possível na época — ${ }_{1}^{4}$ apoiava-se em longo trabalho de aproximação com os bairros da cidade. Como indicava o jornal Diário da Tarde às vésperas da reta final da campanha, 
o deputado Jorge Carone prepara-se para empreender grande "rush" eleitoral, à medida que se aproximam as eleições. 0 candidato republicano, com pouco mais de cinco mêses de campanha, já percorreu quase todas as vilas e bairros da cidade, tendo a sua candidatura encontrado a melhor receptividade com grande entusiasmo popular. ${ }^{5}$

Ao reconhecer a centralidade da população periférica da cidade para a vitória eleitoral, o candidato apostava numa campanha longa, com a presença nesses territórios. 0 rush final que empreenderia significava o retorno às localidades que visitara ao longo dos meses anteriores. Em seus comícios, apontava para um problema central comum aos locais e se apresentava como demanda urgente: a água. Com sérias dificuldades para capitação hídrica, a prefeitura não era capaz de atender à demanda da capital mineira, situação que atingia mais drasticamente as periferias (Mesquita, 2013:107-108).

Além disso, Carone se dizia o grande realizador, sendo responsável pela aprovação de inúmeros projetos como deputado estadual, entre os quais o "que possibilitou a construção do Estádio Minas Gerais - cujas obras estão em andamento - com novos recursos oriundos da Loteria do Estado". ${ }^{6}$ Não raro, sua fotografia era inserida ao lado de uma imagem da maquete do novo estádio, suscitando a ideia de um quase idealizador da iniciativa.

Nylton Velloso tinha importante trajetória na Fecomércio, no Serviço Social do Comércio (Sesc) e no Serviço Nacional de Aprendizagem Industrial (Senai) do estado. Era filho de um bem-sucedido comerciário que, inclusive, batizava a colônia de férias do Sesc, intitulada "Sylla Velloso". 7 Suas iniciativas buscavam articular a principal base eleitoral da UDN, formada pelas classes industriais, comerciais, e pelos profissionais liberais, com grupos populares localizados na periferia de Belo Horizonte.

Entre o amplo espectro de apoiadores de Nylton Velloso, incluíam-se os Diários Associados, responsáveis pela publicação do Diário da Tarde (DT), no qual se observou uma exaustiva cobertura de sua campanha, com notícias de atos e matérias sobre suas propostas.

Esse periódico vespertino, de perfil mais popular em relação ao coirmão Estado de Minas, dedicava-se principalmente à abordagem de temas esportivos, policiais e do cotidiano da capital mineira. Assim, constituiu-se em fonte interessante para os propósitos deste estudo, uma vez que, por longos anos, manteve colunas dedicadas ao futebol amador, com destaque para aquela denominada "Notas da Várzea".

Em sua cobertura, ressaltava, além dos jantares e das reuniões com a alta roda da cidade, os inúmeros comícios de Nylton Velloso nas vilas e nos bairros. Nas notícias acerca desses atos de campanha, não era rara a percepção da presença de grupos ligados ao futebol de várzea em Belo Horizonte. 
Em ato ocorrido na região da Parada da Abadia, por exemplo, noticiava-se que "em nome do bairro falou o sr. Bichara Pedro Elias, que representava ainda o Monte Azul Esporte Clube". ${ }^{8} \mathrm{Ou}$, como no comício no Universitário, no qual, "em nome do bairro, falou o sr. Nelson Santana de Jesus, que lembrou os grandes melhoramentos de que carece a região". 9 Nesse caso, tratava-se do fundador do Racing Esporte Clube, tradicional agremiação do lugar, criada nos anos 1950. ${ }^{10}$

Tal presença não se resumia às aparições de integrantes das agremiações nos comícios. Como relata o DT sobre o ato de campanha que teve lugar no bairro Santo André:

0 comício realizado naquele bairro foi um dos mais concorridos de quantos já se realizaram em Belo Horizonte, sob ambiente dos mais sugestivos, com a Praça Uruguaiana inteiramente enfeitada para receber o candidato e ainda com a participação de várias escolas de samba e desfile de clubes de futebol, que manifestaram, de maneira categórica, o apoio que emprestam ao nome dos srs. Nilton Veloso e Guimarães Alves como candidatos à Prefeito e Vice-Prefeito de Belo Horizonte. ${ }^{11}$

Entre as agremiações varzeanas presentes, foram destacadas "Rio Branco Futebol Clube, União Esporte Clube, Rio Negro Futebol Clube, Chave de Ouro Esporte Clube, Associação Atlética Santista, Bangu Atlético Clube e Corintians Atlético Clube". ${ }^{12}$ Em atos como esse, escolas de samba e clubes de futebol amador reforçavam a vinculação do candidato com os setores populares. Não por acaso, mais uma vez as agremiações carnavalescas seriam requisitadas, agora para o comício final, que, na praça Rio Branco, no início da avenida Afonso Pena, reuniria grandes nomes udenistas, como Milton Campos, Pedro Aleixo e Edgard da Mata Machado. ${ }^{13}$

Outra candidatura que daria a ver a temática do futebol de várzea naquele ano de 1962 era a empreendida por José Maria Rabelo. Vinculado a partido de menor expressão, o PSB, o jornalista que se notabilizara por sua atuação no jornal Binômio, do qual era proprietário, se apresentava como o candidato que representava os movimentos urbanos, inclusive contando com o apoio declarado da Federação de Trabalhadores Favelados de Belo Horizonte (FTFBH), ao lado do candidato a vice-prefeito, pelo PTB, Geraldo Bizzoto (Oliveira, 2014: 267).

Sem a mesma cobertura por parte do Diário da Tarde, na reta final da campanha, o candidato do PSB passou a veicular anúncios pagos, destacados como "Editado pelo Comitê de Jornalistas pró-José Maria", os quais noticiavam seus atos. Ali, ele lançava desafios como o de transparência das fontes de receita de campanha, reforçando o slogan do qual se apropriara da luta do tostão contra o milhão. ${ }^{14}$ Como estratégia para atrair as pessoas ao seu comitê central, onde podiam retirar as cédulas de votação, oferecia passeios gratuitos de helicóptero, o mesmo que usava em seu rush final para visitar um grande número de bairros. ${ }^{15}$ 
Entre os atos de campanha previstos na agenda oficial do candidato, destaca-se o "Comício no bairro Glória, na Associação Atlética Nôvo Ideal - rua Hércules, 120". ${ }^{16}$ Não por acaso, no mesmo dia desse ato, o candidato anunciava a seguinte promessa:

\section{Campos de futebol serão dos clubes amadores}

José Maria anunciou que um dos seus primeiros atos na Prefeitura será a desapropriação de todos os terrenos onde haja um campo de futebol. A medida visa a beneficiar os clubes amadoristas que praticam o futebol em condições precárias, já que seus campos se situam sempre em terrenos cujos donos de um momento para o outro podem sacrificar o divertimento de muitos à especulação imobiliária.17

Com essa proposta, o candidato prometia atacar um problema que se tornava cada vez mais grave para as agremiações varzeanas da cidade. Ao apontar para os riscos da especulação imobiliária, opunha-se sobretudo a um de seus desafetos, o maior proprietário de terras da cidade, a quem acusava constantemente de grileiro nas páginas do Binômio: Antônio Luciano Pereira Filho. Este, por sua vez, estimulado por Juscelino Kubitschek, de quem José Maria Rabelo era adversário, também se lançava à disputa eleitoral, tentando pela primeira vez uma vaga como deputado federal.

Ao longo das décadas de 1940 e 1950, Antônio Luciano formou um verdadeiro império que envolvia canaviais pelo interior do estado e grande quantidade de terrenos em Belo Horizonte, correspondente a vários bairros que se formariam depois. Era proprietário ainda de cinemas, hotéis e um banco, o Financial. ${ }^{18}$ Por ser o principal especulador imobiliário da cidade, tinha em seus lotes grande quantidade de campos de clubes varzeanos, fato que não foi ignorado na campanha. Por duas ocasiões, foram publicados anúncios no Diário da Tarde. Um deles dizia o seguinte:

\section{Convite}

Convidamos tôdos os clubes amadoristas de Belo Horizonte, notadamente os que possuem campo de futebol em terreno de propriedade do "Dr. Antônio Luciano Pereira Filho", para comparecerem á reunião que será realizada dia 27 (quinta-feira) do corrente, ás 20 horas, á rua Erê, 207 - Prado (Ludol), a fim de serem tratados assuntos de interêsse do Futebol Amador.

Belo Horizonte, 25 de setembro de $1962^{19}$

Aproveitando-se de amplo espectro de clubes que tinham os campos sediados em seus terrenos, o candidato a deputado federal podia mobilizar várias pessoas para a reunião, cujos fins não ficam claros, mas que, pela data do ocorrido, provavelmente teria relação com o pleito. 
SOBRE ELEIÇÕES, FESTIVAIS E RESOLUÇÃO DE PROBLEMAS: FUTEBOL DE VÁRZEA E REDES POLÍTICAS LOCAIS EM BELO HORIZONTE (1962-1965)

Alguns candidatos a vereador se apresentavam como representantes das agremiações varzeanas. Foi o caso do jornalista Palmério Ferreira Filho, assim propagandeado pelo DT:

Palmério Ferreira Filho, velho servidor dos "Diários Associados" e grande protetor do esporte amador da Capital, principalmente dos chamados pequenos clubes, dentre os quais o seu, que é o Juventus, do bairro do Carlos Prates, atendendo a insistência de amigos, resolveu aceitar o lançamento de sua candidatura, pelo PRT, ao cargo de vereador, nas eleições que se aproximam. O nosso companheiro de trabalho, numa rápida palestra com a reportagem, declarou que, se eleito, protegerá, ainda mais o esporte amador belorizontino. Na foto, Palmério em palestra com 0 repórter. ${ }^{20}$

Os episódios citados acima corroboram a ideia de que, em períodos eleitorais, o futebol de várzea fazia parte da preocupação de candidatos tanto a vagas no Executivo quanto no Legislativo. A despeito da filiação política, a preocupação com o tema parecia parte da estratégia adotada por todas as vertentes na busca de votos junto às classes populares urbanas, percebidas como grupo determinante do sucesso em qualquer pleito.

A questão que se coloca com base nessa constatação se refere à forma com que tal preocupação com o tema era ou poderia ser aproveitada pelos participantes do circuito varzeano. Uma visão muito compartilhada no senso comum acerca do futebol amador em grandes centros brasileiros é a de que se tratava de um grupo pouco articulado e despolitizado que, em períodos de eleição, cederia apoio ao primeiro candidato que lhes oferecesse um jogo de camisas ou qualquer outro material esportivo. A presença de envolvidos com a modalidade em comícios e reuniões, ou a cessão de sedes de equipes para ato de campanha, seria indício dessa troca de favores oportunista em períodos de votação? Há evidências que permitiriam outra interpretação possível para o fenômeno?

Para compreender melhor o problema, recorrem-se a estudos recentes dos campos da história, da antropologia e da sociologia que apontam chaves de análise importantes para o enquadramento do tema. Uma leitura pautada no tradicional debate populista brasileiro tenderia a enxergar nesse fenômeno mais uma constatação de relações de manipulação que marcaram o período. Como defendido por Ferreira (2001: 84), essa noção era um dos elementos do tripé conceitual de interpretações que tiveram em Francisco Weffort seu principal autor (Gomes, 2001:29). Tal perspectiva, contudo, recebeu uma série de críticas nas últimas décadas, as quais pretenderam reposicionar o debate, em especial sob o ponto de vista das classes trabalhadoras (Gomes, 2005; French, 1995; Silva e Costa, 2001).

Investigações ainda mais recentes têm ressaltado a necessidade de compreensão dessas relações políticas não como meras ações pontuais em tempos de votação, mas como parte de 
uma rede duradoura de vínculos entre moradores de bairros periféricos das grandes cidades e líderes municipais e estaduais. Tais debates reposicionam as interpretações do sucesso eleitoral de governantes com base em carisma e em conexões muito mais palpáveis a partir de entidades comunitárias de variadas naturezas, a exemplo de comitês partidários e associações de bairro, recreativas, culturais e desportivas (Duarte e Fontes, 2004; Duarte, 2002; Fontes, 2008 e 2017: 191-216; Leal, 2011).

Do mesmo modo, a mobilização de conceitos como o de "clientelismo" e "patronagem" levaria à compreensão do fenômeno como mais uma expressão da fórmula da mera troca de favores por votos, como se consolidou em boa parte do debate nacional e internacional sobre tema (Carvalho, 1998: 130-153; Combes, 2011: 13-32). A leitura tradicional do fenômeno, que parte do pressuposto de um desenvolvimento linear das democracias pelo mundo, tem sido colocada em xeque, por exemplo, quando se examinam experiências recentes de países africanos, nos quais relações de reciprocidade se mostram importantes para a articulação entre a lógica eleitoral e as formas tradicionais de interação das populações com os líderes locais (Banégas, 2011: 33-48; Manirakiza, 2010: 103-122).

Apesar da percepção das eleições como um tempo forte das relações políticas (Palmeira e Heredia, 2010), uma série de estudos antropológicos tem se dedicado a examinar tais práticas fora desse período (Kuschnir e Carneiro, 1999: 241). Como destaca Bezerra em relação a estudos que não tratam o clientelismo propriamente como fato sociológico, mas como mero desvio do sistema democrático,

a dimensão propriamente sociológica dessas trocas é deixada de lado. Assim, as mediações necessárias para que os benefícios sejam concedidos e os votos obtidos não chegam a ser examinados. Entre outros aspectos, não é levado em conta o intervalo de tempo que existe entre a concessão dos favores ou benefício público e os votos, por conseguinte, as práticas — como as que são responsáveis pela demonstração de interesse na continuidade da relação (correspondências, pequenos favores, visitas etc.) — que se interpõem entre estes atos (Bezerra, 1999: 17, grifo nosso).

Exames recentes do contexto contemporâneo argentino têm contribuído para uma crítica ao conceito de clientelismo, com investigações que partem do esforço dos pesquisadores para realizar uma imersão nas comunidades ou nos grupos que estabelecem esses tipos de interações (Auyero, 2012; Ossona, 2014 e Vommaro; Quirós, 2011: 65-84). Entre os estudos, destaca-se o de Javier Auyero, que aponta para novas possibilidades interpretativas. Como indica 0 autor para o caso das relações entre líderes locais peronistas e a comunidade de um bairro da periferia da grande Buenos Aires, 
A "troca de favores por votos" no centro da noção de clientelismo político não representa adequadamente a realidade muito mais complexa de relações duradouras, narrativas e identidades que são construídas no funcionamento diário dos círculos íntimos. A escolha do desusado termo "resolução de problemas mediante intervenção política personalizada" não tenta anular a análise do controle político que a distribuição de favores, bens e serviços promove (e que a noção de clientelismo político acentua). Pelo contrário, é na afluência de tentativas das elites políticas de controlar os setores populares e as estratégias que esses adotam para resolver seus problemas que os aspectos mais interessantes da reprodução e das transformações dessa ordem política acontecem. (tradução do autor. 2012:230-231)

el "intercambio de favores por votos" en el centro de la noción de clientelismo político no representa adecuadamente la realidad mucho más compleja de relaciones duraderas, narrativas e identidades que son construidas en el funcionamiento diario de los círculos íntimos. La elección del extraño término "resolución de problemas mediante intervención política personalizada" no intenta anular el análisis del control político que la distribución de favores, bienes e servicios promueve (y que la noción de clientelismo político acentúa). Por el contrario, es en la concurrencia de los intentos de las elites políticas por controlar a los sectores populares y las estrategias que éstos adoptan para resolver sus problemas en donde los aspectos más interesantes de la reproducción y las transformaciones de este orden político ocurren (2012: 230-231).

Ao adotar a categoria "resolução de problemas mediante intervenção política personalizada", o sociólogo argentino ressalta aspectos omitidos pela interpretação clientelista, a exemplo das relações duradouras estabelecidas entre lideranças e grupos a elas vinculados, dos aspectos simbólicos e não meramente utilitários dessas interações, bem como do grau de agência das classes populares. Essas, mesmo que em posição subalterna, são capazes de incidir sobre a atuação dos potentados com vistas ao atendimento de suas demandas, não sendo meras vítimas de uma manipulação que acontece à sua revelia.

Tendo em vista o debate sobre relações de poder entre grupos políticos institucionalizados com intenções eleitorais e classes populares urbanas, compreende-se que a adoção de uma perspectiva centrada nas formas de organização e de efetivo desenvolvimento dessas interações na busca da resolução de problemas e no atendimento de demandas se mostra mais profícua para a análise dos dados que se apresentam. Ao se partir da noção de uma rede que se estrutura para além do momento do pleito, cabe investigar se é possível encontrar indícios de articulações que se prolongavam no tempo e pensar de que maneira, no contexto do futebol de várzea, esses laços eram cultivados. Por fim, deve-se tentar identificar a agência dos atores integrantes das agremiações esportivas no estabelecimento 
dessas interações, percebendo-os como integrantes ativos dos processos, e não como meros alvos de manipulação.

\section{A VÁRZEA E A MANUTENÇÃO DE RELAÇÕES DE RECIPROCIDADE}

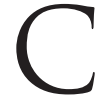

omo apontado acima, na disputa política municipal daquele ano, por várias vezes, o tema do futebol de várzea apareceu, seja com a participação de membros das agremiações, seja com a realização de reuniões nas dependências dos clubes, ou, ainda, com a apresentação de promessas de campanha voltadas ao setor. Ao que parecia, candidatos tomavam aquele como um tema para se conectar aos setores populares urbanos, grupo fundamental para o sucesso eleitoral, assim como os membros das associações esportivas viam naquele contexto uma possibilidade de estreitarem laços com futuros mandatários.

Normalmente restrito às pequenas colunas publicadas no Diário da Tarde, que se concentravam na divulgação dos resultados das partidas e em algumas questões mais próprias da organização esportiva, o futebol de várzea, durante as eleições, era apresentado de forma diversa, e suas conexões eram expostas mais claramente. Apesar da ênfase ganha nesse período, essa prática se relacionou de outras formas com as forças políticas, tanto por vias institucionais, como o Conselho Municipal de Esportes (CME), quanto por meio de relações informais, diretamente com representantes locais.

Criado, em 1948, pelo primeiro prefeito eleito, Otacílio Negrão de Lima, o CME foi o principal canal de relacionamento do futebol de várzea com a prefeitura. Em inícios dos anos 1960, contudo, estava praticamente desativado, como indicava o DT ao comentar a nomeação de uma nova direção, já nos meses finais do mandato do prefeito Amintas de Barros.

Está reorganizado o Conselho de Esportes. 0 prefeito Amintas de Barros, cumprindo sua promessa de candidato, escolheu os elementos que integrarão o orgão municipal de auxilio ao amadorismo. Agora, com recursos financeiros o prefeito houve por bem saldar o compromisso com aqueles que com ele conviveram por mais de 4 anos, na presidencia da Junta Disciplinar Desportiva. Integrado ás dificuldades dos amadoristas, o prefeito somente esperou a oportunidade para revolucionar a várzea. 0 C.M.E. teve especial carinho na sua constituição, considerando, principalmente, o desejo de amparar, efetivamente, áqueles que necessitam de auxilio da Municipalidade. Vários campos varzeanos serão remodelados, outros construídos e alguns, possuirão muros protetores. ${ }^{21}$

Apesar da expectativa rápida de posse dos conselheiros, esta aconteceu apenas em julho, há menos de seis meses do fim do mandato de Amintas de Barros. ${ }^{22}$ Como indicado no trecho acima, o prefeito tinha familiaridade com o tema, já que atuara na Junta Disciplinar Desportiva (JDD), órgão vinculado à Federação Mineira de Futebol (FMF), responsável pelo julgamento de processos disciplinares contra clubes e jogadores. Composto por profissionais de educação 
física, atletas, jornalistas e dirigentes, caberia ao CME administrar os recursos destinados à manutenção de agremiações e espaços de jogo.

Após sua recomposição, o colegiado passava a dispor de um trator para realizar melhorias nos campos. ${ }^{23}$ Para organizar a disponibilização do maquinário e de recursos financeiros, o CME, tão logo empossado, baixava instruções para ingresso de solicitação dos clubes e convocava reunião na sede do Departamento de Futebol Amador (DFA). ${ }^{24}$

Passado o período eleitoral, o CME voltaria à inatividade. Em 1963, assumiu a prefeitura Jorge Carone Filho, do Partido Republicano (PR), que, depois de longa campanha pelos bairros, desbancara o favorito Nylton Velloso, da UDN. Passados quase dois anos do mandato do novo chefe do Executivo municipal, noticiava-se uma mobilização do setor varzeano.

Um abaixo-assinado contendo assinaturas de todos os presidentes dos clubes amadores será entregue ao prefeito Jorge Carone Filho, solicitando ao mesmo, a reorganização imediata do Conselho Municipal de Esportes, órgão criado e regulamentado para servir à várzea. A inatividade daquele órgão de há muito vem prejudicando o esporte amador, que pouco a pouco tende a desaparecer por falta de local para jogos e treinos. ${ }^{25}$

Já num momento pós-golpe, enquanto Jorge Carone se equilibrava ante as pressões da oposição no Legislativo, os varzeanos se organizavam para requerer a retomada das atividades do CME. O colegiado, ao que parecia, havia sido remodelado, dois anos antes, apenas como parte da estratégia eleitoral de Amintas de Barros, que se lançava como deputado federal, cargo para o qual seria escolhido. Ainda nesse contexto, os dirigentes de clubes de futebol amador pretendiam organizar uma comissão que se dirigiria ao novo prefeito solicitando a construção de campos em terrenos na região da Pampulha. ${ }^{26}$

Apesar da mobilização dos integrantes das agremiações e do ensaio de retomada do Conselho Municipal de Esportes na gestão de Amintas de Barros, o cenário do início dos anos 1960 era de ausência de canais institucionais oficiais para o desenvolvimento de políticas voltadas ao futebol de várzea em Belo Horizonte. Num contexto no qual as pressões da demanda de terrenos já se faziam sentir, em especial para os clubes mais antigos, com campos próximos à região central da cidade, outras estratégias eram necessárias para a manutenção de seus espaços de jogo, de suas atividades e, por consequência, de sua sobrevivência.

Seja por meio da memória social presente nas entrevistas dos envolvidos com os clubes varzeanos da capital mineira, seja na documentação impressa, muitos indícios apontam para uma intensa mobilização das agremiações e de seus dirigentes com vistas à articulação junto a forças políticas. Para tanto, utilizavam-se de sua inserção e, por vezes, liderança junto às comunidades dos bairros, assim como de formas de construção de vínculos bem próprias de 
uma "cultura esportiva popular", baseada no desejo de realização de partidas em todos os fins de semana, com promoção de jogos a partir das mais diferentes fórmulas, como amistosos, excursões, festivais, partidas festivas e torneios avulsos.

Nessa medida, uma dessas fórmulas se tornaria um dos mais ricos momentos de visibilidade e de encenação de laços de reciprocidade construídos entre os integrantes dos clubes e toda uma rede de apoiadores: os festivais. Esse modo de disputa ocorria sobretudo por conta do aniversário da entidade e se realizava ao longo de um fim de semana ou de um domingo. Reunia, em seu programa, diversas partidas entre as diferentes equipes das agremiações, desde as categorias menores, formadas por garotos, passando por clubes convidados, até 0 time principal masculino adulto.

Para cada um dos jogos, era designado um adversário, seja um clube da região, seja um time de renome. Todas as disputas previam premiação específica, sendo convidadas pessoas para assumirem a condição de patronos do troféu, responsáveis pela compra do artefato que era oferecido aos vencedores. Padrinhos ou madrinhas da bola eram comuns, aos quais cabia ofertar o material esportivo que seria utilizado num determinado certame. Outra figura recorrente nessas festividades eram as rainhas, escolhidas entre uma das garotas da comunidade — ela se apresentava no embate final, a chamada "Prova de Honra", e oferecia o prêmio aos ganhadores.

Por fim, havia os homenageados, pessoas a quem a entidade varzeana proporcionava contraprestação, em favor de benefícios conferidos ao longo do ano ou com intenções de garantir aproximação futura. Os festivais assumiam formato altamente ritualizado, no qual se encenavam diversos laços de reciprocidade (Mauss, 2003: 183-314) que eram atualizados naquele momento. A identificação dos participantes da cerimônia ajuda a compreender as redes com as quais cada agremiação se articulava.

Nessa perspectiva, um exemplo muito recorrente era o de homenagens à imprensa, tanto aos veículos quanto aos jornalistas propriamente ditos. Para os clubes, a garantia da divulgação constante de seus feitos era uma importante forma de alcance de prestígio no meio varzeano. A equipe do Natal F.C. tinha seus jogos recorrentemente reportados nas páginas do DT, demonstrando ter boa entrada entre os cronistas esportivos. Não à toa, seu festival anunciava as seguintes homenagens:

No dia 25 será realizada a parte esportiva no campo do Paulistano F.C., no Calafate. Na primeira prova Natal x Radio In[confidencia, patrono: sr.] João de Oliveira, homenageados: Radio Inconfidencia e Radio Itatiaia; segunda prova: Natal F.C. x Acre F.C., patrono sr. Flavio dos Reis Correa; homenageados, Diarios Associados, 0 Diario e 0 Debate. ${ }^{27}$ 
Como dito acima, homenagens tinham o intuito de reafirmar laços de reciprocidade, significando uma deferência da agremiação a quem houvesse prestado um serviço ou fornecido algum tipo de ajuda. Veículos de imprensa como Rádio Inconfidência, Rádio Itatiaia e Diário da Tarde, este ligado aos Diários Associados, se notabilizavam por manter noticiário especialmente voltado para a várzea. Em outro caso, o Príncipe E. C. laurearia os jornalistas Sérgio Ferrara e Dirceu Pereira, ${ }^{28}$ figuras ligadas à crônica esportiva e com vínculos com o Grêmio Mineiro de Esportes e o Pitangui Esporte Clube, respectivamente.

Os jogos de reciprocidade dos clubes varzeanos eram variados. A mobilização do reconhecimento pessoal como moeda de troca era muito perceptível nos festivais, quando o nome do patrono, ou seja, o responsável pela compra do troféu colocado em disputa em cada prova, era gravado na taça e se eternizava na galeria de conquistas do vencedor. Um caso interessante é o de uma excursão do Republicano à cidade vizinha de Betim, quando a equipe seguiu "em condução especial, denominada 'Sebastião de Souza Viana - Tatão', em homenagem àquele diretor pelos seus relevantes serviços prestados ao clube". ${ }^{29}$ Provavelmente por ser a pessoa que custeara o transporte que levava time e torcedores, o dirigente teve seu nome associado ao veículo como contraprestação por parte da entidade esportiva.

Em outra ocasião, o DT anunciava:

O Esporte Clube Lunense fará realizar domingo, bem cuidado programa de festividades com que promoverá o batismo de seu estádio que receberá o nome de "Antonio Luciano", homenagem ao deputado federal recentemente eleito.

\section{PROVA DE HONRA}

Como ponto alto das festividades, jogarão as equipes principais do Lunense e do Bonsucesso. Será patrono o sr. Aristeu Pereira e homenageado o deputado federal Antonio Luciano Pereira, cujo nome será dado ao estádio do clube promotor das festividades. ${ }^{30}$

Como abordado na primeira seção do artigo, o então deputado Antônio Luciano era o maior proprietário de terras em Belo Horizonte. Entre suas estratégias para garantir a posse dos lotes e evitar eventuais ocupações, recorrentemente cedia espaço a clubes varzeanos para que instalassem seus campos de jogo. Tal relação, que contemplava interesses mútuos, era reforçada com a realização de homenagens, como a proporcionada pelo Lunense. Um bom convívio com o empresário poderia, quem sabe, garantir outros benefícios, como a construção de dependências, o que não era incomum em se tratando de agremiações que se mantinham em suas áreas. ${ }^{31}$

Na campanha para prefeito de 1962, talvez tenha sido Jorge Carone, entre os candidatos que tinham mais espaço nas páginas do DT, aquele que menos demonstrava articulação com a 
várzea. Há que se considerar, contudo, que as notícias sobre seus atos eram bem menos recorrentes do que as do seu principal adversário, Nylton Velloso. A favor do novo prefeito pesava a lei que aprovara durante o mandato de deputado estadual que previa um fundo para a construção de "estadinhos" voltados ao futebol amador, que seria coordenado pela Diretoria de Esportes, órgão estadual, e que já tinha, em 1963, dezenas de milhões de cruzeiros em caixa. ${ }^{32}$

Talvez como forma de superar esse distanciamento, em seu primeiro ano de mandato como prefeito, observou-se um grande esforço por parte de várias agremiações para garantir uma aproximação. Não por acaso, o chefe do executivo municipal se tornou objeto de várias homenagens nas provas de honra de diversos festivais, a exemplo dos da Associação Atlética Formosa ${ }^{33}$ e do Fluminense Futebol Clube. ${ }^{34}$ Um torneio com seu nome também foi realizado, sendo vencido pelo Rosário Esporte Clube. ${ }^{35}$ Até uma agremiação intitulada Jorge Carone Esporte Clube foi fundada naquele ano. ${ }^{36}$

Ao Social Olímpico Ferroviário, campeão do campeonato da cidade de 1962, promovido pelo DFA, caberia a distinção de ter o prefeito como patrono da prova de honra do festival pela passagem de seu $35^{\circ}$ aniversário. ${ }^{37}$

Foi um festival esportivo promovido pela Associação Atlética Cachoeirinha, naquele ano de 1963, o qual envolveria provas de atletismo e partidas de futebol, que evidenciou melhor as articulações empreendidas pelas agremiações varzeanas da cidade. Como noticiado pelo DT:

A inauguração do asfalto da Rua Simão Tamm, na Cachoeirinha, realizada no sábado passado, foi festivamente comemorada, num programa organizado pelos moradores do bairro, que começou ás 5 horas, com alvorada e salva de tiros, terminando á noite, com a prova "Jorge Carone Filho", reunindo corredores das principais agremiações de Belo Horizonte.

0 importante melhoramento foi inaugurado oficialmente á noite, contando com a presença do prefeito Jorge Carone Filho, numa grande concentração popular, defronte à Associação Atlética Cachoeirinha. ${ }^{38}$

A notícia que tinha aparência de matéria paga, prática recorrente das administrações municipais em Belo Horizonte, ainda trazia fotografia do prefeito num palanque (figura 1). 


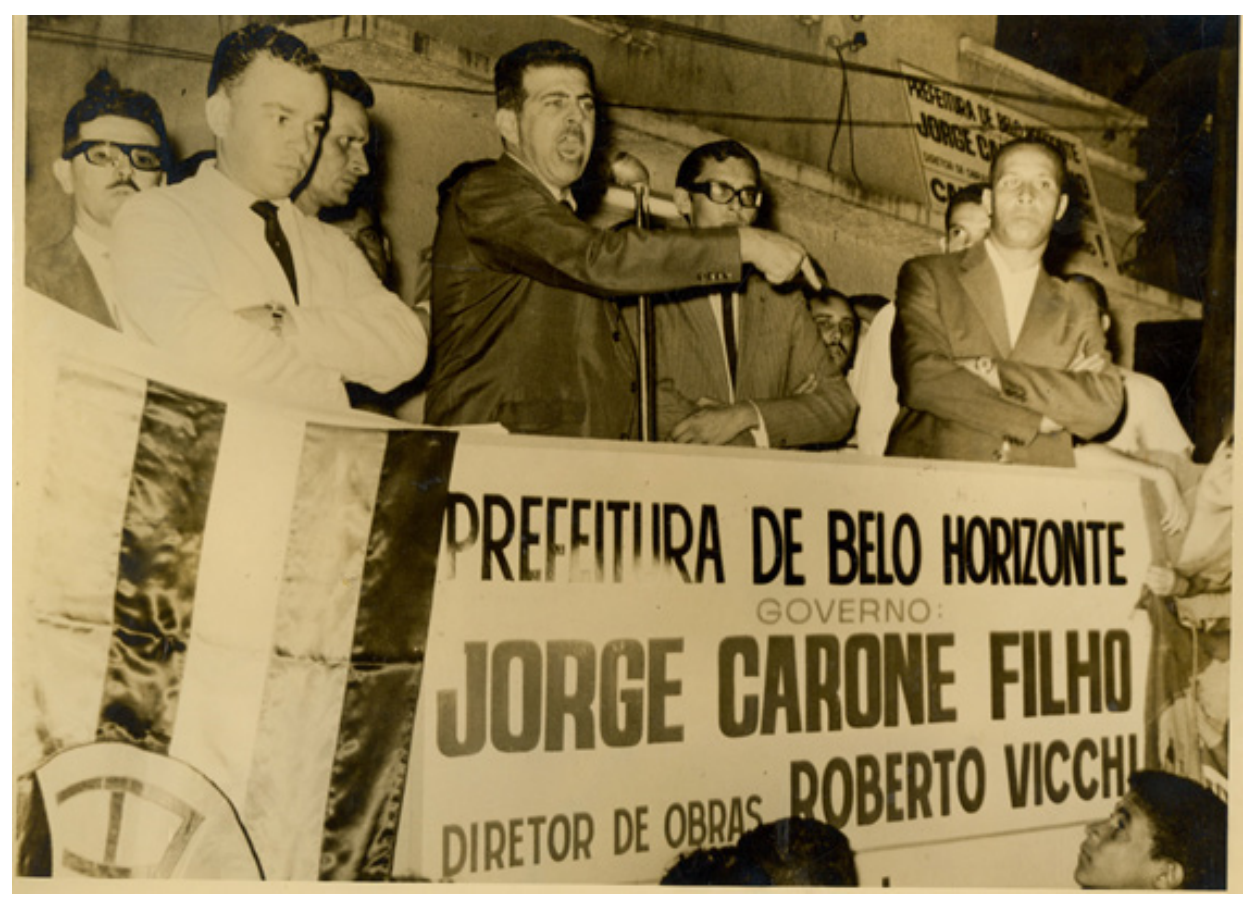

Figura 1 - "Inaugurado o asfaltamento da rua Simão Tamm", Diário da Tarde, Belo Horizonte, 12 de novembro de 1963, Segundo Caderno, p. 2. ACERVO JORNAL ESTADO DE MINAS.

Proferindo um enérgico discurso sobre o que parece ser um palanque, o prefeito Jorge Carone é ladeado pelo vereador recém-eleito, Geraldo Pereira Sobrinho, que veste terno branco; pelo presidente da Associação Atlética Cachoeirinha, de braços cruzados, olhando para a câmera; e por Joaquim Gonçalves da Silva, reconhecido árbitro de futebol que era motorista de táxi por profissão. À frente, vê-se uma faixa da prefeitura, com dados da obra, sobre a qual se estende uma bandeira tricolor, provavelmente preta, branca e vermelha, as cores da agremiação varzeana anfitriã. Bem abaixo, quase fora do quadro, está o público.

Como revelava uma notícia publicada dias antes, a "Corrida do Asfalto", como era intitulada a festividade, estava ao menos em sua segunda edição, já que fora realizada no ano anterior. Corredores ligados a várias agremiações, muitas delas varzeanas, competiriam pelo troféu Jorge Carone Filho. Antecedendo a prova atlética final, haveria uma disputa futebolística em que as equipes Gogó da Ema e Açougue Santa Cruz se bateriam na prova "Vereador Geraldo Pereira Sobrinho". 39 
Não obstante a notícia posterior ao evento, em que amplo destaque era dado ao prefeito e à sua realização no bairro Cachoeirinha, a matéria anterior indicava se tratar de uma festividade que já se tornava recorrente no lugar. Assim, ao que parece, a administração municipal se aproveitava da ocasião, que mobilizava o meio varzeano e o atletismo local, para visibilizar a obra. Para a Associação Atlética Cachoeirinha, a presença de Jorge Carone e do vereador Geraldo Pereira Sobrinho, que tinha sua base na região, reforçava a importância da festa e projetava a agremiação, com a presença de seu presidente na tribuna de honra e as cores do clube representadas. Ademais, apresentava a associação e seus membros como importantes mediadores de benefícios para a região.

Vereadores com fortes bases regionais também poderiam ser notados em meio às homenagens. Era o caso de Antonio Menezes Soares, que chegara à Câmara Municipal em 1963, militando pelo Partido Social Progressista (PSP), e que teria, desde o início de seu mandato, uma atuação voltada para problemas locais, incluindo os relativos às agremiações varzeanas. No fim de 1964, ele interveio a favor do Minas Brasil Futebol Clube, que, como contrapartida, realizou um torneio em referência ao edil, como destacava o DT:

Em partida válida pelo Torneio Vereador Antonio Menezes, conseguiu o Minas Brasil Futebol Clube, agremiação do Bairro da Graça, domingo ultimo mais uma expressiva vitória.

\section{CAMPO PRÓPRIO}

0 vereador Antonio de Menezes, depois de muitos esforços junto ao sr. Prefeito da Capital conseguiu autorização para que o Minas Brasil construisse sua praça de esportes na Avenida Cristiano Machado perto da rua Jacui, sendo que o trator arranjado pelo sr. Antonio de Menezes iniciará os serviços no próximo sábado. ${ }^{40}$

A nota acima expõe bem o ciclo de reciprocidade: 0 vereador era homenageado por ter intermediado a cessão de terreno e benfeitorias junto à prefeitura, enquanto o clube beneficiado promovia um torneio com o nome do político responsável e em comemoração à disponibilização do campo, o que o projetava no meio varzeano e junto à comunidade do bairro. Antônio Menezes demonstrava sua vocação de solucionador de problemas ao viabilizar não só a autorização da prefeitura, como também um trator para as melhorias na área. Sua ação incidiria sobre a região considerada seu reduto eleitoral, identificada como o bairro Sagrada Família e adjacências. ${ }^{41}$

Com a ausência de uma instância municipal que fosse capaz de conduzir as políticas para o esporte amador na cidade, como deveria ser o CME, a relação direta com integrantes do Executivo e do Legislativo municipais era um caminho quase natural dos clubes na tentativa de 
garantir seus interesses. Em algumas situações, a atuação podia ser sem qualquer mediação, como no caso do vereador do PTB que se candidatara a vice-prefeito em 1962: Geraldo Bizzoto. Presidente do tradicional Tremedal, do bairro Carlos Prates, ainda naquele ano eleitoral, o edil ingressaria com projeto de declaração de utilidade pública em favor da agremiação que dirigia, ${ }^{42}$ o qual seria aprovado pouco depois. ${ }^{43}$

A garantia por lei da proteção de interesses de clubes varzeanos começava a ganhar forma no início dos anos 1960, mas rapidamente perderia espaço com a ascensão da ditadura. 0 caso mais emblemático desse período foi o do Pitangui Esporte Clube, que conseguiu garantir a doação do seu terreno, então pertencente à prefeitura. Como apontava o DT: "Movimenta-se a diretoria do Pitangui, clube da Lagoinha, para obter definitivamente, da municipalidade o terreno onde tem seu campo de futebol." 44

No passado, o clube já havia conseguido a aprovação de lei, que, contudo, fora vetada pelo prefeito. ${ }^{45}$ Agora, a iniciativa seria retomada, com o desfecho favorável em 1963, quando, após nova interdição do Executivo, a Câmara Municipal derrubou o veto e promulgou uma lei que autorizou a doação do terreno até hoje ocupado pelo Pitangui Esporte Clube. ${ }^{46}$

A transferência em definitivo da propriedade só aconteceu dois anos depois, já sob a tutela do prefeito Oswaldo Pierucetti. A condução do novo prefeito se deu numa conjuntura pós-golpe de 1964, quando, depois de o prefeito eleito Jorge Carone Filho sofrer impeachment no início de 1965, houve a indicação e a posse do mandatário municipal sob ordens do governo estadual. Em que pese a condução não democrática do novo chefe do executivo local, o Pitangui, agremiação beneficiada, seguia o mesmo rito de homenagens, como indicou o DT:

Comemorando a conquista em definitivo do terreno onde tem seu estádio, o Pitangui fará realizar domingo um festival, tendo como prova de fundo o interestadual reunindo a equipe amadora pitanguiense e o Nacional da cidade capixaba de Itaguassú.

Na oportunidade irá o clube alvi-rubro varzeano prestar homenagem ao Prefeito, presidente da Câmara Municipal, outras autoridades e imprensa esportiva da Capital. ${ }^{47}$

A realização de homenagens seguia sendo um mecanismo corriqueiro de reforço da reciprocidade entre os clubes e as forças políticas. Após os esforços de aprovação de uma lei que favorecia o clube e a possível atuação do prefeito na tramitação do processo, o Pitangui oferecia sua contraprestação em forma de reconhecimento público e deferência durante 0 evento em celebração à conquista do bem mais importante que uma agremiação varzeana poderia ter: um campo de jogo. 
Na fase final do intervalo democrático, o cenário que se conformava para a relação entre o futebol de várzea e o poder público local era o de vínculos cada vez mais baseados na articulação direta entre clubes e representantes, entre eles o prefeito ou os vereadores. A desmobilização de órgãos dedicados ao tema, como o CME, conduzia os membros das agremiações amadoristas em busca de soluções individuais com a construção de laços de reciprocidade com os líderes políticos locais, capazes de auxiliá-los nas resoluções de problemas.

Ao examinar o momento eleitoral de forma isolada, corre-se o risco de considerar que tais aproximações entre clubes e forças políticas locais eram pontuais e se resumiriam a encenações próprias desse contexto. Contudo, ao acompanhar as práticas cotidianas dessas associações esportivas populares, percebe-se a constituição de uma rede de resolução de problemas que constituía um emaranhado de relações contínuas de reciprocidades assimétricas que, por um lado, atendia a demandas locais e, por outro, fomentava acúmulos de capitais de naturezas diversas, em especial política.

As agremiações varzeanas e seus membros demonstravam ter consciência de sua inserção nessa rede, por isso promoviam ocasiões de afirmação das aproximações com os líderes, o que eventualmente poderia se converter em benefício para a continuidade e a melhoria de suas atividades. Da mesma forma, políticos indicavam estar atentos aos códigos próprios de uma "cultura esportiva popular" com a qual se articulavam, assumindo os papéis que thes cabiam nessas interações. A manutenção desses vínculos se mostraria decisiva para os clubes amadores na manutenção de seus espaços numa cidade em franco processo de transformação e ajuda a compreender a atual conformação da prática nos dias de hoje.

\section{NOTAS}

1 Conferir verbete biográfico VELOSO, Nilton, DHBB/CPDOC, disponivel em: http://www.fgv.br/cpdoc/acervo/ dicionarios/verbete-biografico/veloso-nilton. Acesso em: 26 abr. 2019, e "Afirma-se cada vez mais a vitória de Nylton Veloso", Diário da Tarde, Belo Horizonte, 27 de setembro de 1962, p. 5.

2 Conferir verbete biográfico CARONE, Jorge, DHBB/CPDOC, disponivel em: http://www.fgv.br/cpdoc/acervo/ dicionarios/verbete-biografico/jorge-carone-filho. Acesso em: 26 abr. 2019, e "Vilas e bairros recebem Carone com entusiasmo", Diário da Tarde, Belo Horizonte, 31 de agosto de 1962, p. 3.

3 Conferir Oliveira (2014), p. 220-221, e "Notícias de José Maria", Diário da Tarde, Belo Horizonte, 29 de setembro de 1962, p. 7.

4 Conferir verbete biográfico CARONE, Jorge, DHBB/CPDOC, disponível em: http://www.fgv.br/cpdoc/acervo/ dicionarios/verbete-biografico/jorge-carone-filho. Acesso em: 26 abr. 2019.

5 "Vilas e bairros recebem Carone com entusiasmo", Diário da Tarde, Belo Horizonte, 31 de agosto de 1962, p. 3. 
SOBRE ELEIÇÕES, FESTIVAIS E RESOLUÇÃO DE PROBLEMAS: FUTEBOL DE VÁRZEA E REDES POLÍTICAS LOCAIS EM BELO HORIZONTE (1962-1965)

6 "Para prefeito, Jorge Carone Filho", Diário da Tarde, Belo Horizonte, 12 de setembro de 1962, 2 cadernos, p. 1.

7 "Nylton Veloso homenageado em uma de suas grandes obras", Diário da Tarde, Belo Horizonte, 13 de setembro de 1962, p. 5.

8 "Empolga toda a cidade o apoio dos belorizontinos a Nylton Velloso", Diário da Tarde, Belo Horizonte, 11 de setembro de 1962, p. 4.

9 "Moradores de cinco bairro acolheram Nylton Velloso com grande entusiasmo", Diário da Tarde, Belo Horizonte, 11 de setembro de 1962, p. 5.

10 Conferir entrevista de Márcio "Marcinho" Magalhães Junior, Aluísio "Gabiru" Vieira, Nilton Pereira da Silva "Michel", Leonardo "Nadin" Herculano e Jésus Gomes de Arruda concedida ao autor em 10 de agosto de 2017.

11 "Apoteótica recepção a Nylton Velloso em Santo André", Diário da Tarde, Belo Horizonte, 24 de setembro de 1962 , p. 8.

12 Idem.

13 Conferir "Comício da cidade, amanhã, consagrará Nylton Velloso", Diário da Tarde, Belo Horizonte, 28 de setembro de 1962, p. 6.

14 Conferir "Notícias de José Maria", Diário da Tarde, Belo Horizonte, 24 de setembro de 1962, p. 2.

15 Conferir "Notícias de José Maria", Diário da Tarde, Belo Horizonte, 26 de setembro de 1962, p. 2.

16 "Notícias de José Maria", Diário da Tarde, Belo Horizonte, 29 de setembro de 1962, p. 7.

17 Idem.

18 Conferir verbete biográfico PEREIRA FILHO, Antônio Luciano, DHBB/CPDOC, disponível em: http://www. fgv.br/cpdoc/acervo/dicionarios/verbete-biografico/pereira-filho-antonio-luciano. Acesso em: 28 abr. 2019; OLIVEIRA, 2014, p. 295; "Antônio Luciano: o homem e o mito", Diário da Tarde, Belo Horizonte, 29 de outubro de 1973, p. 20.

19 "Convite", Diário da Tarde, Belo Horizonte, 26 de setembro de 1962, p. 9.

20 "Protegerá o esporte amador", Diário da Tarde, Belo Horizonte, 17 de agosto de 1962, p. 7.

21 "Notas da várzea", Diário da Tarde, Belo Horizonte, 8 de maio de 1962, 2 caderno, p. 3.

22 Conferir "Empossados os novos membros do Conselho Municipal de Esportes", Diário da Tarde, Belo Horizonte, 16 de julho de 1962, p. 5.

23 Conferir "Conselho Municipal", Diário da Tarde, Belo Horizonte, $1^{\circ}$ de agosto de 1962, p. 9.

24 Conferir "Notas da Várzea", Diário da Tarde, Belo Horizonte, 24 de julho de 1962, $2^{\circ}$ caderno, p. 2 e "Conselho Municipal", Diário da Tarde, Belo Horizonte, $1{ }^{\circ}$ de agosto de 1962, p. 9.

25 LIMA, Veiga, "Coluna da Várzea", Diário da Tarde, Belo Horizonte, 15 de setembro de 1964, p. 9.

26 Conferir LIMA, Veiga, "Coluna da Várzea", Diário da Tarde, Belo Horizonte, 16 de setembro de 1964, p. 9.

27 "Quinto aniversário do Natal F.C.", Diário da Tarde, Belo Horizonte, 20 de dezembro de 1962, p. 9.

28 "Notas da Várzea", Diário da Tarde, Belo Horizonte, 8 de fevereiro de 1962, 2ºaderno, p. 2. 
29 "Republicano em Betim", Diário da Tarde, Belo Horizonte, 6 de dezembro de 1963, p. 7.

30 "E.C. Lunense inaugura nova praça de esportes", Diário da Tarde, Belo Horizonte, 26 de janeiro de 1963, p. 8.

31 Conferir entrevista de Jair "Lu" Colen Filho concedida ao autor em 18 de setembro de 2016.

32 Conferir "Notas da Várzea", Diário da Tarde, Belo Horizonte, 5 de junho de 1963, p. 9.

33 Conferir "Notas da Várzea", Diário da Tarde, Belo Horizonte, 7 de junho de 1963, p. 8.

34 Conferir "Fluminense comemora seu $41^{\circ}$ aniversário", Diário da Tarde, Belo Horizonte, 4 de novembro de 1963, $2^{\circ}$ caderno, p. 4.

35 Conferir "Rosário (com Didi na direção técnica) foi vencedor no domingo", Diário da Tarde, Belo Horizonte, $1^{\circ}$ de outubro de 1963, p. 9.

36 "Novo Clube Varzeano: Jorge Carone", Diário da Tarde, Belo Horizonte, 20 de agosto de 1963, p. 9.

37 "Notas da Várzea", Diário da Tarde, Belo Horizonte, 18 de abril de 1963, p. 9.

38 "Inaugurado o asfaltamento da rua Simão Tamm", Diário da Tarde, Belo Horizonte, 12 de novembro de $1963,2^{\circ}$ caderno, p. 2.

39 Conferir "Corrida do asfalto: Cachoeirinha faz festa para homenagear Carone", Diário da Tarde, Belo Horizonte, 9 de novembro de 1963, $2^{\circ}$ caderno, p. 7.

40 "Minas-Brasil terá campo próprio", Diário da Tarde, Belo Horizonte, 17 de novembro de 1964, p. 9.

41 "Veja como se vence a eleição com os votos de um bairro só". Diário da Tarde, Belo Horizonte, 23 de novembro de 1972, p. 3.

42 Conferir "DT na Câmara Municipal", Diário da Tarde, Belo Horizonte, 14 de agosto de 1962, p. 2.

43 Conferir "Lei Municipal n 932, de 6 de setembro de 1962".

44 "Câmara Municipal", Diário da Tarde, Belo Horizonte, 14 de agosto de 1962, p. 2.

45 Conferir "Câmara Municipal", Diário da Tarde, Belo Horizonte, 14 de agosto de 1962, p. 2.

46 Conferir "Lei Municipal n 1008", de 15 de fevereiro de 1963.

47 "Pitangui promove torneio", Diário da Tarde, Belo Horizonte, 8 de novembro de 1964, $2^{\circ}$ caderno, p. 2.

\section{REFERÊNCIAS BIBLIOGRÁFICAS}

AUYERO, Javier. La política de los pobres: las prácticas clientelistas del peronismo. Buenos Aires: Manantial, 2012.

BANÉGAS, Richard. Clientelismo electoral y subjetivación política en África: reflexiones a partir del caso de Benín. Revista Desacatos (Cidade do México), n. 36, 2011, p. 33-48.

BEZERRA, Marcos Otávio. Em nome das bases: política, favor e dependência pessoal. Rio de Janeiro: Relume-Dumará, 1999. 
SOBRE ELEIÇÕES, FESTIVAIS E RESOLUÇÃO DE PROBLEMAS: FUTEBOL DE VÁRZEA E REDES POLÍTICAS LOCAIS EM BELO HORIZONTE (1962-1965)

CARVALHO, José Murilo de. Mandonismo, coronelismo, clientelismo: uma discussão conceitual. In: CARVALHO, José Murilo de. Pontos e bordados: escritos de história e política. Belo Horizonte: Editora UFMG, 1998, p. 130-153.

COMBES, Hélène. ¿Dónde estamos com el estudio del clientelismo? Revista Desacatos (Cidade do México), n. 36,2011, p. 13-32.

DUARTE, Adriano Luiz. Cultura popular e cultura política no pós-guerra: redemocratização, populismo e desenvolvimento no bairro da Mooca (1942-1973). Tese (Doutorado em História) - Instituto de Filosofia e Ciências Humanas, Universidade Estadual de Campinas, 2002.

DUARTE, Adriano; FONTES, Paulo. 0 populismo visto da periferia: adhemarismo e janismo nos bairros da Mooca e São Miguel Paulista (1947-1953). Cadernos AEL, v. 11, n. 20-21, 2004, p. 85-122.

FERREIRA, Jorge. 0 nome e a coisa: 0 populismo na política brasileira. In: FERREIRA, Jorge (org.). 0 populismo e sua história: debate e crítica. Rio de Janeiro: Civilização Brasileira, 2001, p. 59-124.

FONTES, Paulo. Um nordeste em São Paulo: trabalhadores migrantes em São Miguel Paulista (1945-1966). Rio de Janeiro: FGV, 2008.

FONTES, Paulo. The Local and the Global: Neighborhoods, Workers and Associations in São Paulo (19451964). International Review of Social History, v. 62, dez. 2017, p. 191-216.

FRENCH, John D. O ABC dos operários: conflitos e alianças de classe em São Paulo (1990-1950). São Paulo: Hucitec/Prefeitura de São Caetano do Sul, 1995.

GOMES, Ângela de Castro Gomes. A invenção do trabalhismo. Rio de Janeiro: FGV, 2005.

GOMES, Ângela de Castro. 0 populismo e as ciências sociais no Brasil: notas sobre a trajetória de um conceito. In: FERREIRA, Jorge (org.). O populismo e sua história: debate e crítica. Rio de Janeiro: Civilização Brasileira, 2001, p. 17-58.

LEAL, Murilo. A reinvenção da classe trabalhadora (1953-1964). Campinas: Editora Unicamp, 2011.

KUSCHNIR, Karina; CARNEIRO, Leandro Piquet. As dimensões subjetivas da política: cultura política e antropologia da política. Estudos Históricos, n. 24, 1999, p. 227-250.

MANIRAKIZA, Désiré. Football amateur au Cameroun: entre clientélisme politique et échanges mutuels. Politique africaine, n. 118, 2010-2, p. 103-122.

MAUSS, Marcel. Ensaio sobre a dádiva: forma e razão da troca nas sociedades arcaicas. In: MAUSS, Marcel. Sociologia e antropologia. São Paulo: Cosac Naify, 2003, p. 183-314.

MESQUITA, Yuri Mello. Jardim de asfalto: água, meio ambiente, canalização e as políticas públicas de saneamento básico em Belo Horizonte (1948-1973). Dissertação (Mestrado em História) - Faculdade de Filosofia e Ciências Humanas, Universidade Federal de Minas Gerais, 2013.

OSSONA, Jorge Luis. Punteros, malandras e porongas: ocupación de tierras y usos políticos de la pobreza. Buenos Aires: Siglo Veintiuno, 2014.

OLIVEIRA, Samuel Silva Rodrigues de. Trabalhadores favelados: o processo de identificação das favelas e os movimentos sociais no Rio de Janeiro e em Belo Horizonte. Tese (Doutorado) - CPDOC, Fundação Getulio Vargas, 2014. 
PALMEIRA, Moacir; HEREDIA, Beatriz Maria Alasia de. Política ambígua. Rio de Janeiro: Relume-Dumarál Nuap, 2010.

SILVA, Fernando Teixeira da; COSTA, Hélio da. Trabalhadores urbanos e populismo: um balanço dos estudos recentes. In: FERREIRA, Jorge (org.). O populismo e sua história: debate e crítica. Rio de Janeiro: Civilização Brasileira, 2001, p. 205-272.

VOMMARO, Gabriel; QUIRÓS, Julieta. Usted vino por su propia decisión: repensar el clientelismo en clave etnográfica. Revista Desacatos (Cidade do México), n. 36, 2011, p. 65-84. 